innumerable monographs on diseases of temperate crops - understandably, because most of the world's plant pathologists are in non-tropical countries. In relation to need there are all too few authoritative texts on diseases of tropical crops; the publication of a new and large book on the subject is, therefore, something of an event.

Dr Paul Holliday has been studying and reporting on diseases of tropical crops for about 30 years, many of them as a member of a pool of plant pathologists, spending much of his time in the tropics and the rest of it at the Commonwealth Mycological Institute at Kew. With this background, there was every reason to expect a firstclass book from the author, and first class it is.

An introduction describes in detail the plan of the book and its parts, and the main sources of information on taxonomy and nomenclature. There follow, in 556 double-column pages of small but readable type, descriptions of fungal pathogens and the diseases they cause in plants grown as crops in the tropics. The fungi are listed alphabetically by perfect state genera with, occasionally, the omission of entries under the imperfect state genera better known to many plant pathologists. A description of the morphology and more general features of each genus is followed by a list of main references to the genus. For each species, under each genus there is a description of the morphology and a critical reference followed by accounts of the diseases it causes - again accompanied by a list of important references, each including the volume and page or abstract number for an abstract in the Review of Applied Mycology or the Review of Plant Pathology; this is particularly useful. The accounts are full and remarkably compact for the amount of information they contain. Quite properly, the emphasis is on factors relevant to diseases in the field and on their control. But there are quite adequate references to physiological, biochemical and related research.

There is an excellent appendix of host plants, their major and minor pathogens, and selected references, a list of common and botanical names of host plants and, finally, two indexes of fungi under perfect and conidial state names.

This book presents a huge amount of information accurately, clearly and systematically, is an excellent work of reference and will remain so for many years. The accounts of the diseases are such that they can also be read with pleasure. Expensive though it be, a thousand copies could be bought for the price of one electron microscope and, where most needed, they will be a lot more useful. They will also require little maintenance and last much longer.

R. K. S. Wood is Professor of Plant Pathology and Head of the Department of Pure and Applied Biology at Imperial College, University of London.

\title{
Topical tropical meteorology
}

\section{Reginald Newell}

Climate and Weather in the Tropics. By $\mathrm{H}$. Riehl. Pp.611. (Academic: 1979.) £28, \$67.50.

STRANGERS to our subject may wonder why the tropics should be accorded a separate treatment in studies of climate and weather. After reading Riehl's book, I suspect that it is the sheer volume of new material available rather than fundamental differences in the characteristic phenomena that prompts this division. Many of the early meteorological studies dealt with the tropics; Trade Winds were analysed for their practical use to shipping, and early ideas about the global general circulation were based (often erroneously) on the tropical Hadley cell circulation.

In the twentieth century, frontal systems and the changing patterns of cyclones and anticyclones began to be explored in depth, both observationally and theoretically, and the focus and excitement switched to middle latitudes. The old ideas of general circulation were replaced by those which gave a pre-eminent role to the large-scale quasi-horizontal eddy processes; theoretical work by Jeffreys was followed by observational studies by Bjerknes, Priestley, and Starr and his colleagues. Most of the observational data came from the middle and high latitudes of the Northern Hemisphere. During and after the Second World War, forecasters from middle latitudes had to ply their trade in the tropics and many tried to translate ideas about middle-latitude systems to those of the tropics, without success. In fact, when data on the general circulation of the tropics became available it was realized that the quasi-steady Hadley cell circulation and the associated Walker circulations in longitudinal planes dominate the tropics, while the eddy processes govern the general circulation of middle latitudes.

There are of course some major differences between the regions: the rather flat surfaces of constant potential temperature in the tropics compared to the steep slopes - the strong baroclinicity of middle latitudes; the easterly jet streams rather than the westerly jets of middle latitudes; the presence of a two-year cycle, with a shift from east to west, in the zonal winds of the tropical lower stratosphere as compared with the one-year seasonal cycle of middle and high latitudes; the large extent of tropical warm ocean, with temperatures greater than about $300 \mathrm{~K}$, which seems to be necessary to spawn and maintain hurricanes; the mean vertical motions which in monsoon regions reverse from winter to summer rather than every few days as in middle latitudes; the dominance of the Earth's vorticity over the local vorticity in middle latitudes; and the strong vertical coupling which characterizes systems of middle latitudes and contrasts with the near independence of the lower and upper troposphere in the tropics. In this book, Riehl describes all the important phenomena and places them in the context of the global general circulation. He seems to have read all that has been written on tropical meteorology and provides an excellent set of references. A notable feature is the inclusion of findings from recent expeditions to the tropics such as the Tropical Atlantic Experiment.

The problems of how energy is transported vertically in the tropics from its source, effectively at the sea surface, and how energy gets into the atmosphere from the warm ocean - both topics that Riehl has contributed to significantly - are dealt with extensively and there is ample material for students to carry the subjects further.

Tropical cyclones and the various ideas about their structure, mechanisms, formation and movement are covered in detail and occupy about one quarter of the book. There is a well-written chapter by Ferdinand Bauer on numerical prediction of hurricanes.

My only major complaint - from which Bauer's chapter is exempt - is that numerous typographical errors are scattered throughout the book; together with the awkward construction of some phrases and poor standardization of units, they often make the text hard to follow. A firm editorial hand needs to be applied before the next edition. Nevertheless, Riehl's book provides a unique source of information and deserves to be read by all meteorologists and to be the standard reference for many years.

Reginald Newell is a Professor of Meteorology in the Department of Meteorology and Physical Oceanography at the Massachusetts Institute of Technology.

\section{TRNA 2}

\section{J.P. Goddard}

Transfer RNA: Biological Aspects. Edited by D. Söll, J.N. Abelson and P.R. Schimmel. Pp.578. (Cold Spring Harbor Laboratory: 1980.) \$70, \$84 outside USA.

THE publication of this book follows approximately six months after that of its companion volume Transfer RNA: Structure, Properties and Recognition (reviewed in Nature 284, 287; 1980). The format of the two volumes is similar. Thus the contributors, who were participants at the Transfer RNA Meeting at Cold Spring Harbor in August 1978, have given us here a series of readable, authoritative and objective articles covering all the biological aspects of tRNA, except synthetase recognition, aminoacylation and ribosome 